\title{
Successful radical resection of pancreatic head carcinoma in a patient with replaced right hepatic artery originating from posterior inferior pancreaticoduodenal artery: a case report
}

\author{
Yusuke Sakamoto, Takahisa Fujikawa (iD and Akira Tanaka
}

\begin{abstract}
Anatomical variations of hepatic arteries may be problematic in pancreaticoduodenectomy (PD). We experienced pancreatic head cancer in a patient with rare variation of hepatic artery and performed PD successfully with the resection of this artery. A 75-year-old woman showed pancreatic head tumor on CT. Preoperative CT detected rare variation of hepatic artery; posterior segmental branch of right hepatic artery (RHA-PB) originating from posterior inferior pancreaticoduodenal artery. The image also demonstrated that there was a junction between RHA-PB and anterior branch of right hepatic artery (RHA-AB). We performed PD for suspected pancreatic head cancer. We divided RHA-PB for complete resection of cancer because we preoperatively knew that there was the junction between RHA-PB and RHA-AB. She was discharged uneventfully, and there was no evidence of local recurrence throughout the whole course. Careful preoperative assessment of hepatic blood supply is the key to perform successful PD even in this troublesome situation.
\end{abstract}

Keywords: Pancreatic head cancer, Replaced right hepatic artery, Pancreaticoduodenectomy, Preoperative anatomical assessment

\section{Background}

Anatomical variations of hepatic arteries are of great importance for abdominal surgery and interventional radiology. Especially, aberrant right hepatic artery (RHA) may be problematic in pancreaticoduodenectomy (PD) [1]. Resection of this aberrant artery is sometimes necessary to achieve R0 resection of cancer, although it can lead to possible bile duct and liver ischemia.

We experienced locally advanced pancreatic head cancer in a patient with an unusual aberrant RHA and performed PD successfully by sacrificing this vessel without any complications.

\footnotetext{
* Correspondence: fujikawa-t@kokurakinen.or.jp Department of Surgery, Kokura Memorial Hospital, 3-2-1 Asano, Kokurakita-ku, Kitakyushu, Fukuoka 802-8555, Japan
}

\section{Case presentation}

A 75-year-old woman with a history of surgical intervention for aortic aneurysm showed dilatation of her main pancreatic duct and pancreatic head tumor on CT scan at an annual medical check-up. Endoscopic ultrasoundguided fine needle aspiration of the pancreatic head tumor was performed, and the result was group 4. She was referred to our department for the surgical treatment of suspected pancreatic head cancer.

Preoperative enhanced high-resolution CT detected pancreatic head tumor and major posterior segmental branch of RHA (RHA-PB) which originated from posterior inferior pancreaticoduodenal artery (PIPDA) and run through the tumor (Fig. 1). The image also demonstrated that there was a junction between RHA-PB and minor anterior segmental branch of RHA (RHA-AB) at the hilar portion (Fig. 2). 


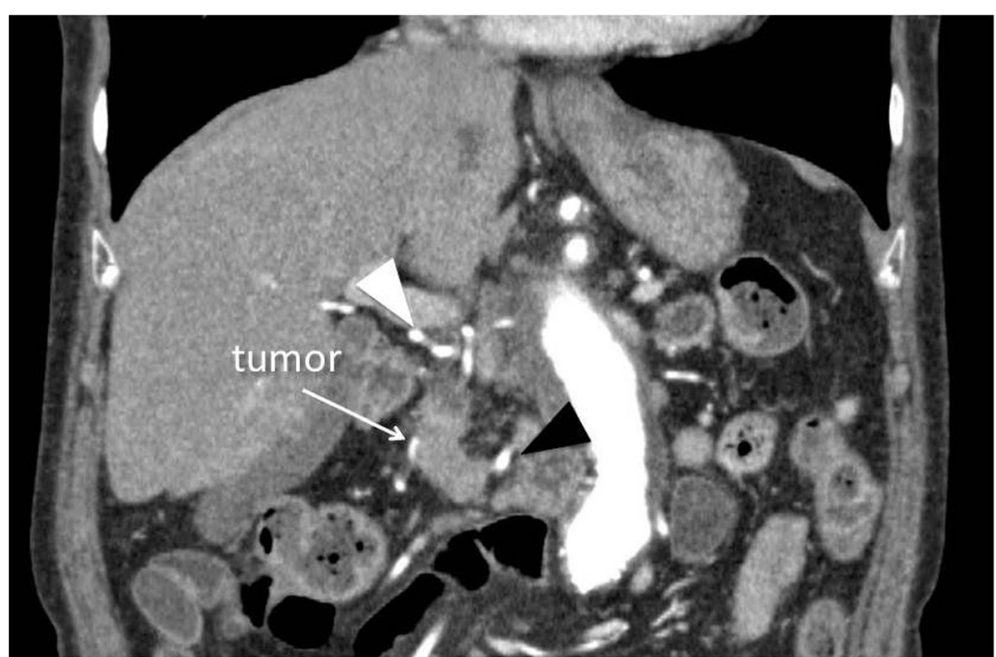

Fig. 1 An enhanced CT scan demonstrated there was a tumor (labeled as "tumor") in the pancreatic head and RHA-PB (white arrow head) originating from PIPDA (black arrow head) was running through the tumor

She received PD combined with regional lymph node dissection. At laparotomy, RHA-PB was isolated from the hepatoduodenal ligament and confirmed that it originated from PIPDA in accordance with the preoperative findings, which revealed to run through the tumor. To preserve RHA-PB, we had to preserve posterior pancreaticoduodenal arcade and the common trunk of PIPDA, which decreased the curability of the tumor. We ensured that the color of the liver did not change after clamping of RHA-PB. Finally, we ligated and divided RHA-PB for complete resection of the pancreatic head tumor because we knew from the preoperative images that there was the junction between RHA-PB and RHA-AB at the hilar portion. We performed the operation without any complication and achieved R0 resection macroscopically (duration of surgery, $355 \mathrm{~min}$; blood loss, $220 \mathrm{~mL}$ ).

Her postoperative course was uneventful, and she was discharged on POD15 without hepatic or biliary ischemia. The pathological examination revealed that the tumor was diagnosed as an adenocarcinoma of the pancreas. The tumor invasion was seen near the intraparenchymal vessels (Fig. 3), but R0 resection was performed.

Although she died from chronic heart failure 13 months after the operation, local recurrence had not be seen throughout the whole course.

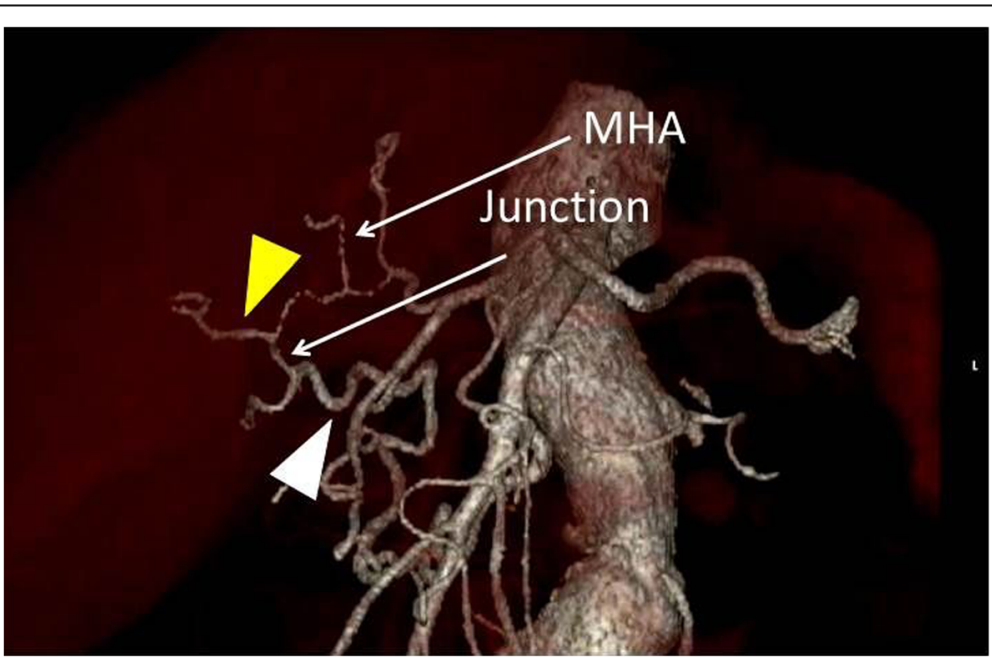

Fig. 2 A 3D reconstruction of CT showed there were middle hepatic artery (labeled as "MHA") and a junction (labeled as "junction") between RHA-PB (white arrow head) and RHA-AB (yellow arrow head) at the hilar portion 


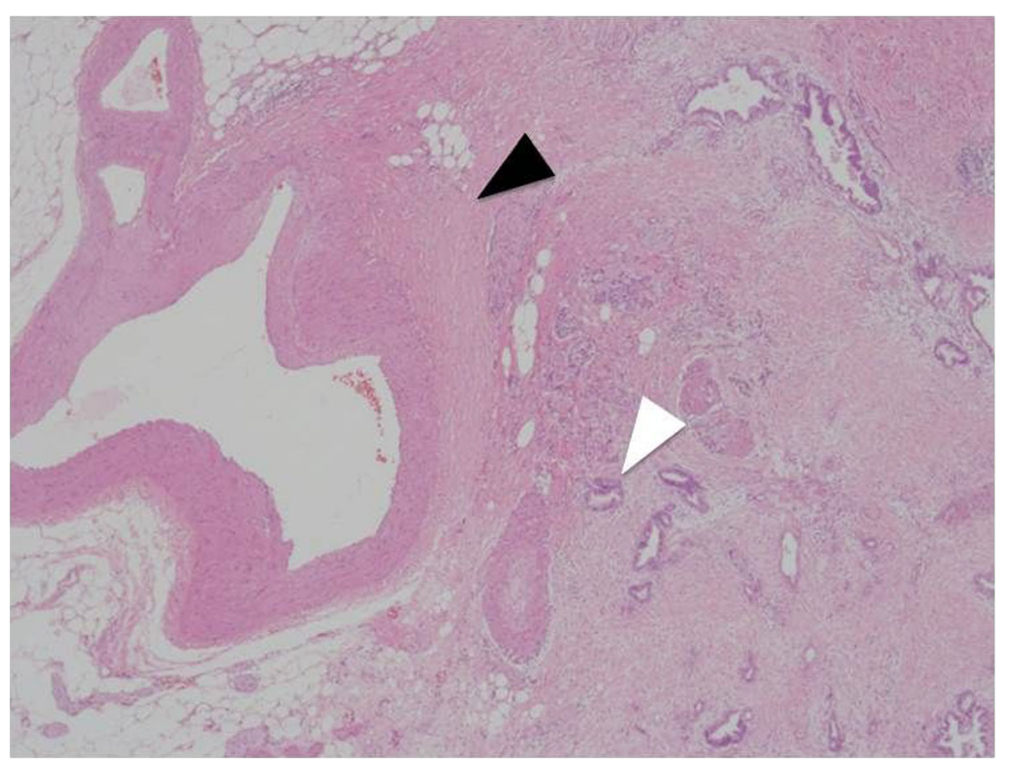

Fig. 3 The pathological examination revealed that the tumor (white arrow head) invasion was seen near the intraparenchymal vessels (black arrow head)

\section{Discussion}

We experienced pancreatic head cancer in a patient with rare variation of hepatic artery; RHA-PB originating from PIPDA. We preoperatively identified this unusual aberrant artery and the junction at the hilar portion, which led to successful PD with the resection of this unusual aberrant artery.

We could not find a report on RHA-PB originating from PIPDA. In 1966, Michels et al. described 10 types of anatomic variations of hepatic artery [2] and many authors commonly used Michels' classification in examining anatomic variations of hepatic artery. However, several authors reported rare variations which could not be classified according to Michels (Table 1) [3-8]. To the best of our knowledge, rare variations which were not described in Michels' classification existed in 1.8$18 \%$ of cases, and the variation we encountered in this case has not been reported before.

We performed PD successfully with the resection of this aberrant artery. The optimal surgical strategy in patients with aberrant RHA is under discussion. El Amrani et al. reported that aberrant RHA was preserved in most cases (87\%) [1]. Postoperative and oncological outcomes seemed unaffected by RHA variation provided that the aberrant RHA was identified and correctly managed intraoperatively. Okada et al. reported PD was a feasible and safe surgical modality in patients with replaced RHA similar to patients with normal variants [9]. However, it was technically and oncologically difficult to achieve sufficient surgical margins for pancreatic cancer in patients with replaced RHA, regardless of whether there was tumor abutment. They suggested that replaced RHA whose root was situated within $10 \mathrm{~mm}$ from tumor should be divided to improve the rate of $\mathrm{R} 0$ resection with preoperative therapy (i.e., coil embolization of replaced RHA). Jah et al. reported that aberrant RHA could have three different anatomical courses in relation to the head of the pancreas: posterior route with respect to the head of the pancreas (type I), intraparenchymal route (type II), and deeper route in the superior mesenteric venous groove (type III) [10]. Intraparenchymal aberrant RHA (type II) and those which were involved by tumor should require en bloc resection of the vessel. They also recommended reconstruction in patients where aberrant RHA was large or was thought to represent replaced RHA in en bloc resection of the vessel.

In these chaotic situations, we suggest the following strategy for aberrant RHA in PD. When there is aberrant RHA in preoperative image, you should assess the route with respect to the head of the pancreas and the position of tumor. When aberrant RHA is type I or type III, or the tumor is situated more than $10 \mathrm{~mm}$ from aberrant RHA [9], aberrant RHA may be preserved. When aberrant RHA is classified to the other case, en bloc resection of aberrant RHA should be performed. Preoperative coil embolization or reconstruction may be recommended in patient whose aberrant RHA is large or has no collaterals, or liver function is abnormal. In our case, because the tumor was located near the course of RHA$\mathrm{PB}$ at the pancreatic head, RHA-PB was sacrificed. After clamping test, we successfully divided this artery without reconstruction. It might be safe to perform preoperative angiography to know the direction of blood flow of the junction between RHA-PB and PHA-AB because RHA$\mathrm{PB}$ was relatively large. If necessary, we might consider preoperative coil embolization or reconstruction. Careful preoperative assessment of hepatic blood supply and 
Table 1 Hepatic arterial variations incompatible with the descriptions in the Michels' classification

\begin{tabular}{|c|c|c|}
\hline Author & $\begin{array}{l}\text { Number of } \\
\text { patients }\end{array}$ & Type \\
\hline \multirow[t]{3}{*}{ Ugurel MS } & 1 & $\begin{array}{l}\text { RHA originating from the middle } \\
\text { colic artery }\end{array}$ \\
\hline & 1 & $\mathrm{RHA}$ originating from the aorta \\
\hline & 1 & LHA originating from CHA \\
\hline \multirow[t]{5}{*}{ Yaprak O } & 3 & $\mathrm{RHA}$ originating from CA \\
\hline & 2 & Trifurcation $^{a}$ \\
\hline & 2 & Accessory RHA originating from GDA \\
\hline & 1 & $\begin{array}{l}\text { RHA originating from the aorta and } \\
\text { accessory LHA originating from LGA }\end{array}$ \\
\hline & 1 & $\begin{array}{l}\text { CA bifurcating into different branches } \\
\text { accompanied by replaced RHA } \\
\text { originating from SMA }\end{array}$ \\
\hline \multirow[t]{3}{*}{ Skorzewska A } & 1 & $\begin{array}{l}\text { RHA originating from the aorta and } \\
\text { LHA originating from LGA }\end{array}$ \\
\hline & 1 & Double hepatic artery ${ }^{b}$ \\
\hline & 1 & LHA originating from GDA \\
\hline \multirow[t]{3}{*}{ Araujo Neto SA } & 2 & $\mathrm{RHA}$ originating from CA \\
\hline & 2 & LHA originating from CHA \\
\hline & 2 & Trifurcation $^{a}$ \\
\hline \multirow[t]{7}{*}{ Nemeth K } & 3 & Trifurcation $^{a}$ \\
\hline & 1 & $\begin{array}{l}\text { RHA originating from the proximal } \\
\text { part of } C H A \text { and } C H A \text { trifurcationg } \\
\text { into } L H A, G D A \text {, and } R G A\end{array}$ \\
\hline & 1 & Pentafurcation ${ }^{c}$ \\
\hline & 1 & $\mathrm{RHA}$ originating from $\mathrm{CA}$ \\
\hline & 1 & $\begin{array}{l}\text { RHA originating from the proximal } \\
\text { part of } \mathrm{CHA}\end{array}$ \\
\hline & 1 & RHA-PB originating from $\mathrm{CHA}$ \\
\hline & 1 & $\begin{array}{l}\text { LHA originating from the proximal } \\
\text { part of } \mathrm{CHA}\end{array}$ \\
\hline \multirow[t]{2}{*}{ Thangarajah A } & 7 & double hepatic artery \\
\hline & 11 & Trifurcation $^{a}$ \\
\hline
\end{tabular}

CA celiac axis, GDA gastroduodenal artery, LHA left hepatic artery, LGA left gastric artery, RGA right gastric artery, SMA superior mesenteric artery, $C H A$ common hepatic artery

a"Trifurcation" means CHA trifurcating into RHA, LHA, and GDA

b"Double hepatic artery" means early branching of RHA and LHA from CA

"Pentafurcation" means CHA branching into five arteries, LHA, RHA, artery of segment IV, GDA, and RGA

meticulous intraoperative dissection are the keys to perform PD successfully even in this troublesome situation.

\section{Conclusions}

We experienced rare variation of hepatic artery during the resection of the pancreatic head tumor; RHA-PB originating from PIPDA. Careful preoperative assessment of hepatic artery system and its relationship with tumor and the head of pancreas is the key to perform successful PD even in this troublesome case.

\section{Abbreviations}

AB: Anterior branch; PB: Posterior branch; PD: Pancreaticoduodenectomy; PIPDA: Posterior inferior pancreaticoduodenal artery; RHA: Right hepatic artery

\section{Authors' contributions}

TF participated in the patient's care. YS performed research design, data analysis, and writing of the article. TF and AT participated in revising the manuscript critically. All authors read and approved the final manuscript.

\section{Authors' information}

YS, TF, and AT are the staff surgeons at the Department of Surgery, Kokura Memorial Hospital.

\section{Competing interests}

The authors declare that they have no competing interests.

\section{Consent for publication}

Written informed consent was obtained from the patient for publication of this case report and any accompanying images. A copy of the written consent is available for review by the Editor-in-Chief of this journal.

\section{Publisher's Note}

Springer Nature remains neutral with regard to jurisdictional claims in published maps and institutional affiliations.

Received: 22 February 2017 Accepted: 13 June 2017

Published online: 19 June 2017

References

1. El Amrani M, Pruvot FR, Truant S. Management of the right hepatic artery in pancreaticoduodenectomy: a systematic review. J Gastrointest Oncol. 2016;7:298-305

2. Michels NA. Newer anatomy of the liver and its variant blood supply and collateral circulation. Am J Surg. 1966;112:337-47.

3. Ugurel MS, Battal B, Bozlar U, Nural MS, Tasar M, Ors F, et al. Anatomical variations of hepatic arterial system, coeliac trunk and renal arteries: an analysis with multidetector CT angiography. Br J Radiol. 2010;83(992):661-7.

4. Yaprak O, Demirbas T, Duran C, Dayangac M, Akyildiz M, Tokat Y, et al. Living donor liver hilar variations: surgical approaches and implications. Hepatobiliary Pancreat Dis Int. 2011;10(5):474-9.

5. Skorzewska A, Stajgis P, Grzymislawska M, Rojewska M, Krajecki M, Bruska M, et al. Rare variations of hepatic arteries in association with variable origin of gastroduodenal artery found in multidetector computed tomography angiography. Folia Morphol (Warsz). 2014;73(4):531-5.

6. Araujo Neto SA, Franca HA, de Mello Junior CF, Silva Neto EJ, Negromonte $\mathrm{GR}$, Duarte CM, et al. Anatomical variations of the celiac trunk and hepatic arterial system: an analysis using multidetector computed tomography angiography. Radiol Bras. 2015:48(6):358-62.

7. Nemeth K, Deshpande R, Mathe Z, Szuak A, Kiss M, Korom C, et al. Extrahepatic arteries of the human liver--anatomical variants and surgical relevancies. Transpl Int. 2015;28(10):1216-26.

8. Thangarajah A, Parthasarathy R. Celiac axis, common hepatic and hepatic artery variants as evidenced on MDCT angiography in South Indian population. J Clin Diagn Res. 2016;10(1):TC01-5.

9. Okada K, Kawai M, Hirono S, Miyazawa M, Shimizu A, Kitahata Y, et al. A replaced right hepatic artery adjacent to pancreatic carcinoma should be divided to obtain R0 resection in pancreaticoduodenectomy. Langenbecks Arch Surg. 2015;400(1):57-65.

10. Jah A, Jamieson $\mathrm{N}$, Huguet $\mathrm{E}$, Praseedom $\mathrm{R}$. The implications of the presence of an aberrant right hepatic artery in patients undergoing a pancreaticoduodenectomy. Surg Today. 2009;39(8):669-74. 